\title{
The effect of generic medicines e-learning course via Web 2.0 tools on knowledge of pharmacists and pharmacy students
}

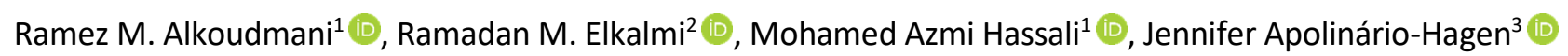 \\ ${ }^{1}$ Department of Social and Administrative Pharmacy, Faculty of Pharmacy, Universiti Sains Malaysia (USM), Penang, Malaysia \\ ${ }^{2}$ Department of Pharmacology, Faculty of Medicine, University of Sebha, Sebha, Libya \\ ${ }^{3}$ Institute of Occupational, Social and Environmental Medicine, Faculty of Medicine, Heinrich Heine University Düsseldorf, Germany
}

Keywords
Arab world
EdTech
Educational technology
E-learning
Online learning
Pharmacy education
Social media
Web 2.0
Correspondence
Ramez M. Alkoudmani
Universiti Sains Malaysia (USM)
Penang
Malaysia
cpe4ever@gmail.com

Keywords

Educational technology

E-learning

Pharmacy education

Social media

\begin{abstract}
Background: Research scoping on e-learning and novel web 2.0 tools in pharmacy education in Arabic Language Speaking Countries (ALSCS) is scarce. Aim and methods: Therefore, this study aimed to develop an online educational course on generic medicines to reveal the views of Arab pharmacists and pharmacy students about emerging technologies in transferring pharmaceutical knowledge and assess the differences in knowledge scores before and after the online educational intervention and the differences in knowledge scores among study subgroups. Results: The total mean knowledge score after attending the online educational intervention significantly increased, from $4.9 \pm 1.68$ to $7.75 \pm 1.75(\mathrm{t}(86)=4.6, p<0.001)$. Providing an online course using web 2.0 tools to transfer pharmaceutical knowledge was viewed as highly positive (mean score $=62.23 \pm 6.08$, range $45-75$ points). Significant sex and status differences were identified post-assessment. Female participants and pharmacists had higher knowledge scores compared with males and students, respectively. Conclusion: The online course development was successfully implemented using Schoology as an online learning management system (LMS) and Facebook as a social network site (SNS). Arab pharmacists and pharmacy students found e-learning and web 2.0 tools to be effective novel technologies in transferring pharmaceutical knowledge.
\end{abstract}

\section{Introduction}

Emerging online educational technologies (EdTech) and web 2.0 tools such as Facebook are used globally in transferring knowledge via the internet. Educators nowadays can design educational materials based on their students' learning styles as they are offering videos, audio, lecture notes, and slides in an interactive elearning environment. Online materials can be navigated and downloaded easily through a learning management system (LMS), helping learners access the course materials and have direct discussions with instructors. Technological, institutional, pedagogical, management, ethical, evaluation, resource and social interaction factors are the main factors that can influence the perceived ease of use and usefulness of e-learning (Basak, Wotto \& Bélanger, 2016). E-learning is playing a crucial role nowadays in pharmacy and medical education. Learners use social network websites (SNSs) and other novel web 2.0 tools to share their knowledge and expertise. Pharmacists and other healthcare professionals (HCPs) can improve their skills via the internet. Several studies have shown that e-learning helps healthcare professionals stay updated with the latest healthcare trends (Lewis et al., 2014; Huynh, 2017; Lee et al., 2018). Although these new trends are promising to push pharmacy and medical education forward, the significant barriers regarding the adaptation of e-learning and new online educational technologies in Arab states have been reported. These barriers include information communication technology (ICT) problems, higher connectivity costs, unequal income distribution, immoral values and dangers to the family and society, the low public reputation of online 
learning as a credible way to gain knowledge, poor education, language barriers with resistance against the English language, the relative absence of Arab initiatives to adopt e-learning, lack of qualified ICT-savvy educators, copyright issues, wars and political conflicts, and the digital divide between Arab states and other countries around the world (Babiker, 2014; Alkoudmani \& Elkalmi, 2015). Pharmacy education and practice continue to evolve in the ALSCs; however, most ALSCs still depend on traditional didactic educational methods in pharmacy education (Kheir et al., 2008). To the best of the authors' knowledge, there were few research efforts in the Arab region concerning using e-learning and novel web 2.0 tools in transferring pharmaceutical knowledge (Alkoudmani \& Elkalmi, 2015). A recent study showed that more than half of pharmacists and pharmacy students were unfamiliar with e-learning (Alkoudmani et al., 2021).

\section{Objectives}

This study is considered the first of its kind in ALSCs and aimed to develop a 4-week online educational course about generic medicines on Schoology and reveal pharmacists and pharmacy students' views about using novel educational technologies in pharmacy education. It also assessed the knowledge of participants before and after enrolling in the e-learning course. Furthermore, the study aimed to investigate the differences in knowledge scores between study subgroups.

\section{Methods}

\section{Study population}

As a web 2.0 tool, Facebook was used to invite Arab pharmacists and pharmacy students to take an online course about generic medicines. A total number of 265 groups on Facebook have been targeted to invite participants. Four hundred fifty persons agreed to join the Facebook group named "Main Course Group". This group has been created to facilitate communication between the course coordinator and study participants. Pharmacists who joined the private group on Facebook were asked to send a photocopy of a certificate proving their latest qualification. Pharmacy students sent a photocopy of the university matric card. The total number of participants enrolled in the online educational course via Schoology was $n=248$ Arab pharmacists and pharmacy students (55.11\% out of 450 ). Those who were not pharmacists or pharmacy students were excluded, as shown in Figure 1. The ethics committee at Kulliyyah of Pharmacy, International Islamic University Malaysia (IIUM), has approved this study.

\section{Study design}

The study design was based on a cohort study (onegroup pre-test-post-test design) to evaluate the effects of a 4-week online course on participants' knowledge about generic medicines. This topic was chosen as a hot topic as global healthcare expenditure is increasing, and using such equivalent alternatives can lead to considerable savings (Cameron \& Laing, 2010; Woerkom et al., 2012). In this study, participants were asked to take an online pre-test to assess their baseline knowledge about generic medicines. Participants then attended an online course entitled "understanding generic medicines: what healthcare professionals should know". The online course was available on Schoology' which has been chosen because of its good reputation among ICT-Savvy educators and its userfriendly navigation of the online material (Joshua, Swastika \& Estiyanti, 2016; Garcia et al., 2018; Sudarwati, 2018). Furthermore, it is well known as an educational platform that facilitates the learning process between instructors and learners via the web (Sicat \& Ed, 2015; Suana et al., 2017).

Participants who completed the online educational intervention were asked to take a final knowledge test on Schoology as a post-intervention assessment. Figure 2 shows the study flowchart. To improve the response rate, certification of achievement was offered as an incentive for participants who fulfilled the online course requirements. Requirements included attending online modules on Schoology, completing all course assignments and discussions, reading articles related to the course topic, and taking the final quiz by a given deadline. All graded online assignments had to be completed by the due date and time. Participants would pass the online course if they got a minimum of $70 \%$ of the final grade. Those who met this requirement were given a certificate of accomplishment.

\section{Description of the online educational course on generic medicines}

The online course was adapted from a paper-based course divided into four major parts, respectively, four modules. Firstly, an introduction to generic medicines general was provided based on definitions according to the World Health Organization (WHO) and the Food and Drug Administration (FDA). The introduction also included a brief explanation of the requirements that generic medicine should meet to be registered. The second module included the benefits of using generic medicines in the safe and cost-effective treatment of chronic illnesses. The third module offered detailed information about the quality, efficacy, and safety of generic medicines. This part focused more on bioequivalent testing and bioavailability. Lastly, the 
fourth module included the essential points to be considered regarding brand switching. The major skills were included in this part, which was ended by a summary and conclusion of the topic.

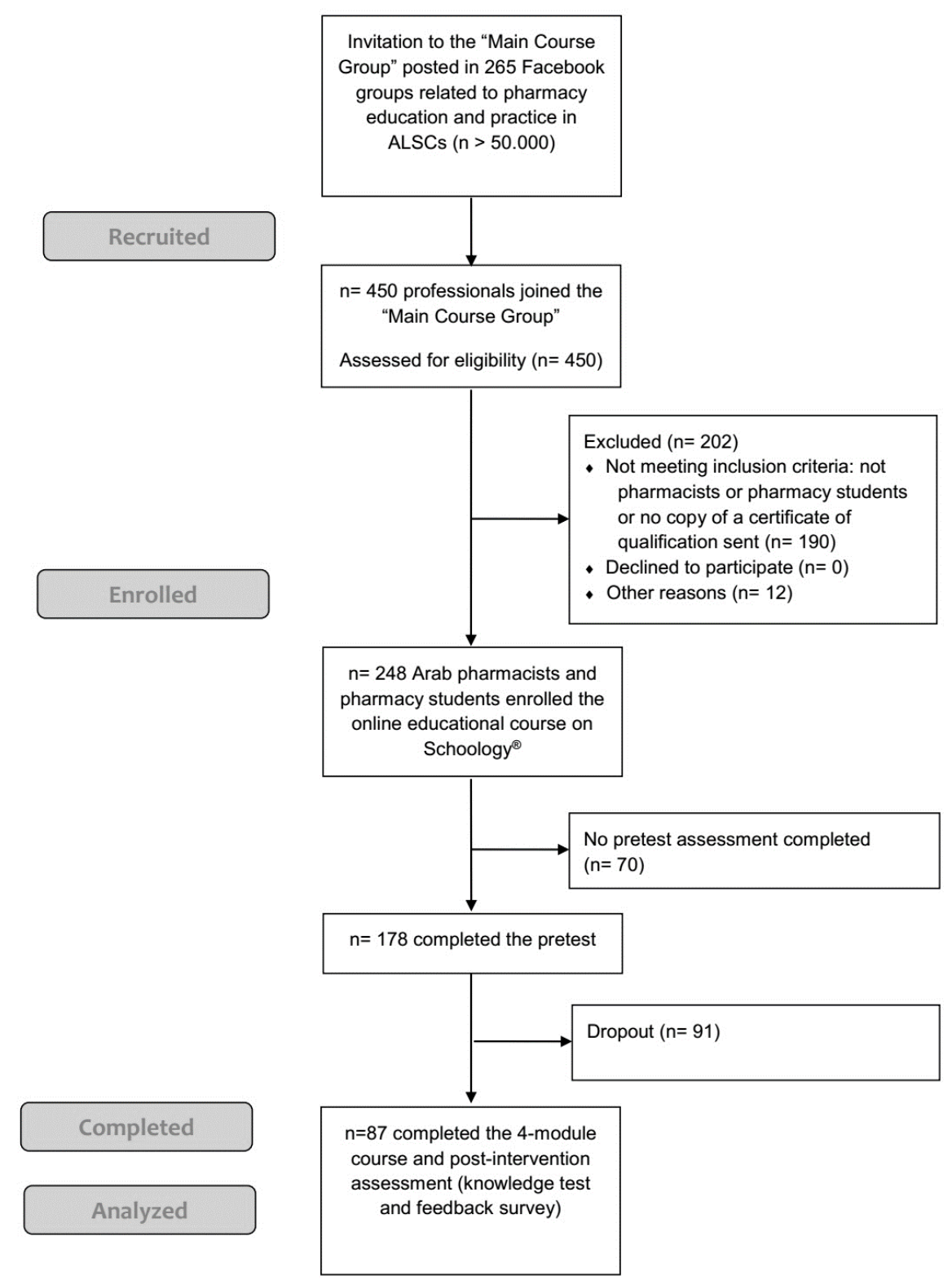

Figure 1: Participant Flow Diagram $(n=87)$ - adapted from CONSORT (2010)

\section{Digitalising the paper-based educational course}

Microsoft PowerPoint was used to create four educational modules. Two to three videos for each module have been created as screencasts using Camtasia Studio. Screencasts have been narrated in both Arabic and English languages as the participants preferred both languages. Each video's length and size have been considered to make sure that videos will be easily downloaded or streamed directly on Schoology. Each module contains its slides as pdf, ppt, and mp3 files. Participants could download slides and mp3 files if they have a slow internet connection. PowerPoint slides were in the English language and tested for content and face validity independently by two pharmacy experts. One of the experts was the main author of the educational course. The validity of the digital form of the paperbased module was measured using a pre-validated instrument (Tezci, Karaca \& Sezginsoy, 2008). Three raters indicated their agreement on the scale statements. The scale includes 41 items covering six domains, which are: (1) audio-visual elements, (2) content, (3) language and expression, (4) functioning, (5) form-shape, and (6) colour. 


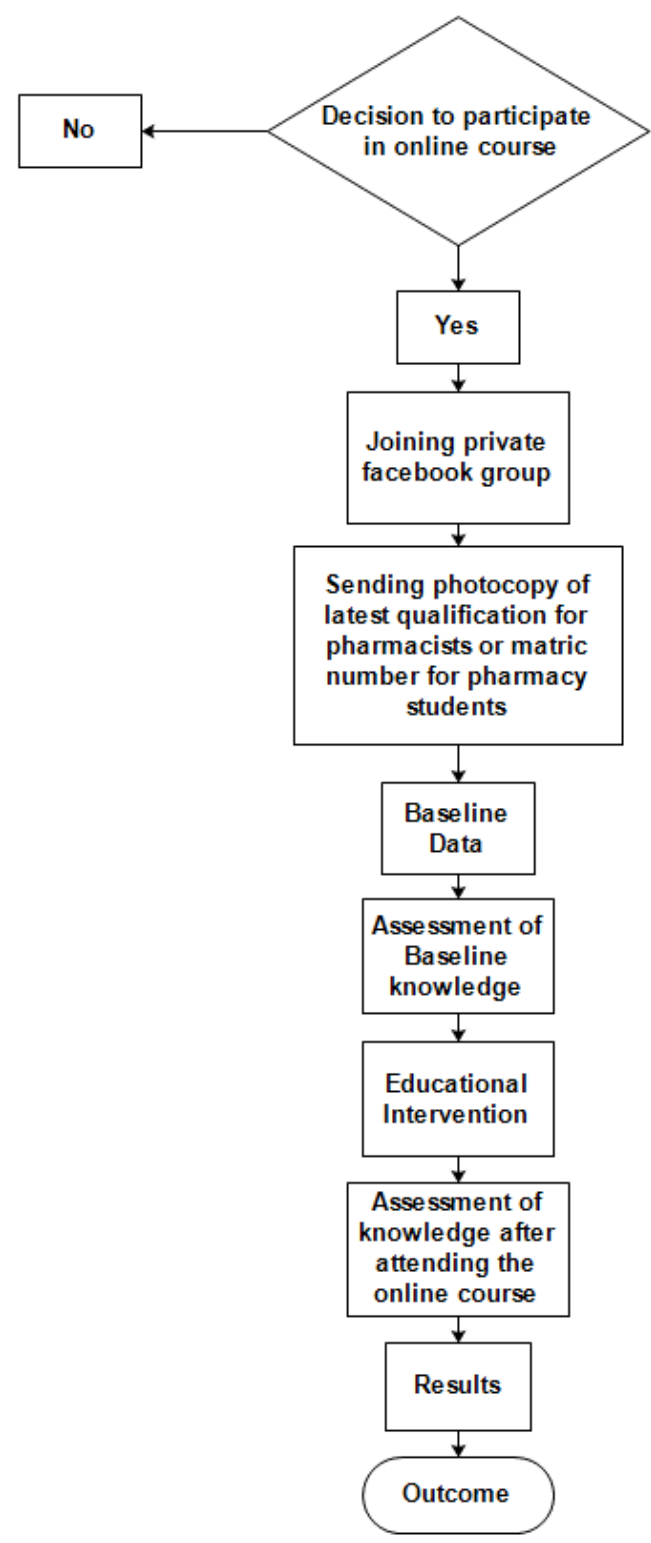

Figure 2: A flowchart of the study design

\section{Instrument development}

The questionnaire was developed primarily in the English language. The initial items were developed based on a literature review and a paper-based course entitled "Understanding Generic Medicines: What Healthcare Professionals Should Know" (Hall et al., 2010; Peska \& Lewis, 2010; Gadbury-Amyot \& Brockman, 2011; Hassali, 2012; DiVall et al., 2013).

The questionnaire included three sections: (1) sociodemographics, (2) knowledge statements, and (3) participants' feedback on the online course. Knowledge statements have been developed based on a validated paper-based module titled "understanding generic medicines: what healthcare professionals should know" (Hassali, 2012). The final questionnaire included 29 items, classified into the following areas. The first section consisted of four items that covered the participants' socio-demographics and a question about the preferred language of instruction for the online course.

The second section consisted of 10 items constructed as multiple-choice questions (MCQs) assessing the knowledge of participants about generic medicines. The online educational module topic was generic medicines and has been recommended by three pharmacy practice researchers as a hot topic, not just in the Arab world but also worldwide. Once participants completed the online course, they were asked to describe the terms of "generic medicine" and "bioavailability", become more familiar with concepts related to "bioequivalence testing" and quality use of generic medicines. The knowledge about generic medicines among Arab pharmacists and pharmacy students was assessed by asking ten multiple-choice questions. The participants' overall pre-test and posttest scores were compared based on the number of questions answered correctly. A score of 1 was given for each correct response and 0 for each wrong answer. The maximum obtainable score was 10 , and the minimum 0 .

The third section of the questionnaire included 15 statements to assess participants' views on the usefulness of the online course. Participants were asked to indicate their agreement on a 5-point Likert scale ranging from 1 ("strongly disagree") to 5 ("strongly agree"). The percentages of the agreement to feedback statements have been merged and expressed as either agreed or strongly agreed if they agreed with any statement, while expressed as disagreed if they disagreed or strongly disagreed with any statement. The internal consistency of the 15-item measure was good with Cronbach's alpha $=0.84$.

The questionnaire was tested for its face and content validity. Face validity was tested by consulting two pharmacy practice lecturers at Kullyyiah of Pharmacy, Kuantan Campus, International Islamic University Malaysia (IIUM). The questionnaire structure was adjusted based on constructive comments by the pharmacy experts. The content validity index (CVI) was tested by four pharmacy education experts and three experts in online learning. Scale-level content validity index, averaging calculation method (S-CVI/Ave) was used to calculate average CVI for the whole instrument (Yusoff, 2019). The average content validity index was excellent $(\mathrm{CVI}=0.822)$.

Procedure: time frame for the administration of the survey and online course

The web survey was constructed using the SurveyMonkey tool and integrated within Schoology as a 
compulsory step to be completed by participants who attended the online course. A tutorial video about Schoology was created to support participants who joined the online course group on Facebook to navigate the course easily. Similarly, the tutorial video was posted in the Facebook group. The pre-educational intervention part of the study includes the socio-demographics items as a web survey and 10 MCQs about generic medicines as a pre-test (knowledge quiz).

The study time frame was one month. The online course consisted of four weeks (i.e. one module per week). At the end of week four, participants who attended the four modules completed the post-test (knowledge quiz). Participants also completed the feedback on the online course, which was offered on Schoology. This step was compulsory to reveal their views about using e-learning and web 2.0 tools in transferring pharmaceutical knowledge. Online course settings on Schoology were set to ensure completing each module before going to the next one. Participants who completed the pre-test part of the study will get the educational intervention and then take the post-test.

\section{Statistical analysis}

Data obtained from the web survey was exported as an SPSS file from SurveyMonkey. SPSS version 22.0 software package (SPSS Inc., Chicago, IL) was used for data analysis. Only completed data sets were considered for statistical analyses. Descriptive and inferential statistics were performed on the dataset. The results were expressed as percentages and frequency to describe categorical variables (e.g. socio-demographics). The assumption of normal distribution was tested using the Kolmogorov-Smirnov test. Parametric tests have been used for the knowledge scores as the distribution of data around the mean was normal. Data received from a Likert scale were analysed statistically as nonparametric data (Pallant, 2020). Values with a significance level of alpha $<0.5(p<0.05)$ were considered statistically significant at confidence interval (Cl) $95 \%$.

\section{Results}

\section{Descriptive data: Socio-demographic characteristics}

The total number of participants who completed the pretest, post-test interventions, and feedback survey were ( $n=87,35.1 \%$ ) out of 248 enrolled participants, as shown in Figure 3.

The majority of participants who completed all online course requirements were females ( $n=69,79.3 \%)$, and about two-thirds of participants were pharmacists $(n=$
$57,65.5 \%)$. The total number of male pharmacists and pharmacy students was $(n=12, n=6)$, respectively, while the total number of female counterparts was $(n=45$, $\mathrm{n}=24$ ). As illustrated in Table I, the vast majority of participants $(n=76,87.4 \%)$ were from ALSCs. About three-quarters of the participants reported that they preferred Arabic and English for e-learning courses $(n=65,74.7 \%)$.

There was no statistically significant relationship in the knowledge about generic medicines between the subgroups pertaining to sex $(p=0.23)$, country of residency $(p=0.08)$, current job status $(p=0.5)$, and language of instruction ( $p=0.63$ ) at pre-assessment. However, there was a statistically significant relationship between sex and post-test knowledge scores $(p=0.005)$. Similarly, there was no statistically significant relationship between post-test knowledge scores and current job status $(p=0.61)$, country of residency $(p=0.6)$ and language of instruction $(p=0.78)$.

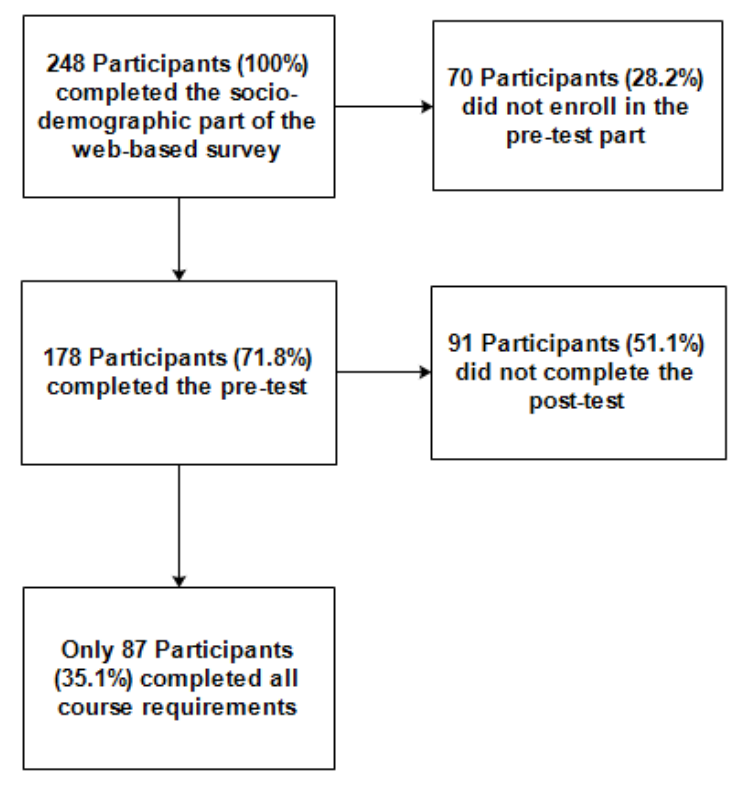

Figure 3: Response rate of participation in the online course

\section{Changes in knowledge scores}

The total mean (M) knowledge score after attending the online educational intervention significantly increased from $4.9 \pm 1.68$ to $7.75 \pm 1.75(\mathrm{t}(86)=4.6, p<0.001)$, with a large within-in group effect size (Cohen's $d=1.69$ ); the total mean difference was $0.83 \pm 1.68$. In the postassessment, there was a tremendous improvement in the proportion of participants having correct responses with a statistically significant difference between the responses to all questions concerning the knowledge domain before and after the online educational course $(p<0.001)$ in Table II. 
Table I: Socio-demographic characteristics of course completers $(n=87)$

\begin{tabular}{lll}
\hline Characteristics & Frequency & (\%) \\
\hline Sex & 18 & 20.7 \\
Male & 69 & 79.3 \\
Female & & 34.5 \\
Job Status & 30 & 65.5 \\
Pharmacy Student & 57 & \\
Pharmacy Practitioner & & 87.4 \\
Country of Residency & 76 & 12.6 \\
Resident in ALSC & 11 & \\
Resident outside ALSC & & 9.2 \\
Preferred Language of Instruction & 8 & 16.1 \\
Arabic & 14 & 74.7 \\
English & 65 & \\
Both Arabic and English & & \\
\hline
\end{tabular}

arabic Language Speaking Country

Table II: Comparison of participants' knowledge before and after the online educational intervention $(n=87)$

\begin{tabular}{|c|c|c|c|}
\hline Multiple-choice questions & $\begin{array}{l}\text { Correct response before } \\
\text { the online intervention } \\
\qquad n(\%)\end{array}$ & $\begin{array}{l}\text { Correct response after } \\
\text { the online intervention } \\
\qquad n(\%)\end{array}$ & $p$-value \\
\hline $\begin{array}{l}\text { 1. Which of the following factors are needed to ensure that a } \\
\text { drug can be regarded as a generic medicine? }\end{array}$ & $70(80.5)$ & $83(95.4)$ & $<0.001^{*}$ \\
\hline 2. What is the importance of pharmacovigilance? & $64(73.6)$ & $75(86.2)$ & $0.015^{*}$ \\
\hline $\begin{array}{l}\text { 3. For quality control purposes, dissolution procedures specified } \\
\text { by the United States Pharmacopeia (USP) are used: }\end{array}$ & $68(78.2)$ & $57(65.5)$ & $0.015^{*}$ \\
\hline $\begin{array}{l}\text { 4. The experimental parameters measured in bioequivalence } \\
\text { studies do not include: }\end{array}$ & $60(69.0)$ & $73(83.9)$ & $0.006^{*}$ \\
\hline $\begin{array}{l}\text { 5. The requirements for two drugs to be bioequivalent are that } \\
\text { the } \mathrm{Cmax} \text { and } \mathrm{AUC} \text { must lie within the range of --------- } \\
\text { associated with } 90 \% \text { confidence intervals }(90 \% \mathrm{CI}) \text {. }\end{array}$ & $38(43.7)$ & 73 (83.9) & $<0.001^{*}$ \\
\hline 6. Why are generic medicines less expensive? & $58(66.7)$ & $60(69.0)$ & 0.64 \\
\hline $\begin{array}{l}\text { 7. When drawing up a risk minimization plan for generic } \\
\text { medicines, the following must be taken into account except: }\end{array}$ & $38(43.7)$ & $38(44.7)$ & 0.74 \\
\hline $\begin{array}{l}\text { 8. Generic medicines can differ from the originator drug in the } \\
\text { composition of active substances }\end{array}$ & $75(86.2)$ & $77(88.5)$ & 0.57 \\
\hline $\begin{array}{l}\text { 9. A generic medicine is assumed to behave in the same way as } \\
\text { the originator }\end{array}$ & $78(89.7)$ & $82(94.3)$ & 0.20 \\
\hline $\begin{array}{l}\text { 10. Another generic medicine of the same effect can serve as a } \\
\text { reference product in bioequivalence testing of generic } \\
\text { medicines }\end{array}$ & $53(60.9)$ & $56(64.4)$ & 0.52 \\
\hline
\end{tabular}

\section{Participants' feedback: Views about the online course}

As shown in Table III, most participants had positive feedback on the online course about generic medicines provided on Schoology (Mean score $=62.23 \pm 6.08$, range 45-75 points).

\section{Subgroup differences in knowledge scores and views}

As shown in Table IV, there was a statistically significant difference in the knowledge about generic medicines between subgroups based on sex $(p=0.037)$ and current job status $(p=0.047)$ at post-assessment. Female participants scored higher than males, and pharmacists got higher scores compared with pharmacy students. However, there was no statistically significant difference in the knowledge about generic medicines between the subgroups pertaining to sex $(p=0.320)$, country of residence $(p=0.874)$, current job status $(p=0.181)$, and language of instruction $(p=0.659)$ at baseline/pre-assessment, and country of residency $(p=0.824)$ and language of instruction $(p=0.938)$ at post-assessment. Participants have been asked to reveal their views about the online course. The vast majority of participants had positive feedback on the online course about generic medicines provided on Schoology (minimum score $=45$, maximum score $=75$, Mean=62.23 \pm 6.08 ). However, there was also no statistically significant difference between feedback total scores and socio-demographic variables such as sex, country of residency, current job status, and language of instruction ( $p=0.631, p=0.654, p=0.529$, $p=0.412$, respectively). 
Table III: Responses to feedback statements regarding the usefulness of the online course $(n=87)$

\begin{tabular}{|c|c|c|}
\hline Feedback Statements & Agree/Strongly & Disagree \\
\hline 1. I found access to the course material flexible with my life duties. & 96.5 & 2.3 \\
\hline 2. I could navigate the module easily. & 88.5 & 2.2 \\
\hline 3. I liked the look and format of the modules. & 96.6 & 3.4 \\
\hline 4. The ability to retrieve the material helps me to enhance my learning. & 92.0 & 7.8 \\
\hline 5. I enjoyed the fact that I can access the modules and my grades with a click of the mouse. & 87.3 & 3.4 \\
\hline 6. Course materials were available in a format that suited me. & 87.3 & 2.3 \\
\hline 7. The online activities helped me to share my ideas. & 75.9 & 3.4 \\
\hline 8. The online activities made studying the course interesting and engaging. & 83.9 & 1.1 \\
\hline 9. The course content was understandable. & 94.2 & 0.0 \\
\hline 10. The course content was appropriate. & 94.2 & 0.0 \\
\hline 11. The course has improved my knowledge on the topic. & 94.2 & 0.0 \\
\hline 12. I feel that I can apply what I have learned confidently. & 86.2 & 0.0 \\
\hline $\begin{array}{l}\text { 13. I found web-based learning more difficult than traditional learning in terms of understanding the } \\
\text { course content. }\end{array}$ & 19.5 & 66.7 \\
\hline 14. The e-learning environment motivated me as a learner. & 90.8 & 0.0 \\
\hline $\begin{array}{l}\text { 15. Online activities with participants and course coordinator allowed me to clarify doubts about the } \\
\text { course material. }\end{array}$ & 80.5 & 2.3 \\
\hline
\end{tabular}

Table IV: The total mean of post-test knowledge scores based on sex and current job status $(n=87)$

\begin{tabular}{|c|c|c|c|c|}
\hline Characteristics & $\begin{array}{l}\text { Total mean of } \\
\text { pre-test scores }\end{array}$ & $\begin{array}{c}\text { Total mean of } \\
\text { post-test scores }\end{array}$ & $\begin{array}{c}\text { Frequency } \\
n(\%)\end{array}$ & P-Value \\
\hline \multicolumn{5}{|l|}{ Sex } \\
\hline Male & 6.44 & 6.72 & $18(20.7)$ & $0.037^{*}$ \\
\hline Female & 7.04 & 8.01 & $69(79.3)$ & \\
\hline Total & 6.92 & 8.0 & $87(100)$ & \\
\hline \multicolumn{5}{|l|}{ Current Job Status } \\
\hline Pharmacy Student & 6.57 & 7.23 & $30(34.5)$ & $0.047^{*}$ \\
\hline Pharmacy Practitioner & 7.10 & 8.02 & $57(65.5)$ & \\
\hline Total & 6.92 & 8.0 & $87(100)$ & \\
\hline
\end{tabular}

*Independent-samples T-test. * $\mathrm{p}<0.05$.

\section{Discussion}

The majority of study participants were females, which was consistent with another study done at the medical college of Cairo University (Abdelhai et al., 2012), likely due to the higher numbers of females who prefer to study and practice the pharmacy profession in the Arab world compared to males (Kheir et al., 2008). Other studies have shown that females who attended online courses were more than male participants (Koch et al., 2010; Ried, 2010; Meckfessel et al., 2011). Similarly, pharmacists were more than pharmacy students. This result was consistent with another study that showed that pharmacists who were 50 years old or younger tend to attend Continuous Pharmacy Education (CPE) programs provided via the internet more (Conte, 2012). Participants had significantly higher knowledge scores and positive views on the online course provided on Schoology upon completion of the educational module. The knowledge scores after attending the online educational intervention increased significantly. This result was consistent with other findings (Hall et al., 2010; Ried, 2010). It reflects the potential of sharing and improving pharmaceutical knowledge using such novel educational methods. However, a study by Öztürk and Dinç demonstrated that there was no difference between the intervention group and the control group on knowledge scores (Öztürk \& Dinç, 2014). Female participants had a significantly higher knowledge score than males at post-intervention assessment. The result of this study is consistent with prior research, showing that e-learning is a flexible and interactive learning approach most suited to women (González-Gómez et al., 2012). Azmi showed that female participants spent more time on LMS than males (Mohamed Azmi H, 2012). Similarly, pharmacists in this study significantly outperformed pharmacy students in knowledge scores, likely because pharmacists are more experienced than pharmacy 
students or more familiar with the educational topic provided.

\section{Views on e-learning course}

The vast majority of participants had highly positive feedback on the online course provided on Schoology. Accessing online course materials was flexible with participants' life duties. This result is consistent with other findings, which showed positive feedback to elearning (Karaksha et al., 2013; Andrew, Ewens \& Maslin-Prothero, 2015). Study participants navigated the online modules easily on Schoology, in line with the results of another study that used Schoology as a learning management system (Schlager, 2016). Participants liked the look and format of the online modules. This result is supported by another study, which showed that students felt the presence of instructor videos in addition to voice-over PowerPoint slides would enhance their learning experiences (Abdulla, 2012). Similarly, retrieving the online educational materials by participants helped them to improve their learning. The asynchronous e-learning model helped participants navigate and review the online course materials at any time. The result of this study is consistent with a study in which students pace themselves to read without time restrictions (Bradshaw \& Lowenstein, 2013).

Moreover, participants accessed the online modules and their grades with a mouse click on Schoology. This result resonates with that of another study, which showed that participants enjoyed accessing the online modules and their grades with a mouse click (Abdulla, 2012). Arab participants found the educational topic, which was about generic medicines, understandable and appropriate. This positive feedback is promising for designing future online modules that could cover more pharmacy practice topics. In this study, all participants found that the course helped them improve their generic medicines knowledge, consistent with previous findings (Crouch, 2009; Gerdprasert et al., 2010; Koch et al., 2010; Bollmeier et al., 2011; Meckfessel et al., 2011).

Also, Arab pharmacists and pharmacy students were confident to apply what they had learnt in the online course in practice. Hall et al. showed that about half of the study participants reported difficulties with the online course. Fortunately, only 1 out of 5 participants found that online learning is harder than traditional learning in terms of understanding the course content (Hall et al., 2010). This positive feedback is promising despite the digital divide between Arab-speaking countries and developed nations with the poor conditions that faced some Arab countries during the study period and the problems of electricity and internet connection, especially in Syria, Libya, and Yemen.

\section{Subgroup differences}

In this study, most participants preferred Arabic and English languages to be used together in the online course. This result showed the acceptance of the Arabic language besides the English language even though most Arab countries used the English language for instruction in pharmacy faculties, except for Iraq and Syria, which used Arabic and English languages (Kheir et al., 2008). The vast majority of participants who completed all course requirements resided in ALSCs at the study time. However, only 87 participants out of $\mathrm{n}=248$ (corresponding to a response rate of $35.1 \%$ ) completed all course requirements.

This response was good despite the barriers preventing Arab participants from completing the online course. This result is consistent with that of another study, which showed the positive views of Arab participants regarding the use of e-learning as a novel educational tool (Babiker, 2014). Furthermore, the result of this study reflects the positive views of Arab citizens to develop their skills and minimise the digital gap between them and citizens of developed nations. The drop-out of participants could be due to the digital gap between Arab countries and developed nations, so not all participants could continue. Other causes could be the unfamiliarity of Arab participants with e-learning and web 2.0 tools. The political and war conflicts that faced some Arab countries during the study period, like Syria, Iraq, Egypt, Libya, and Yemen, negatively affected electricity and the internet connection, both crucial for participants to complete the online course requirements.

\section{Limitations}

Positive attempts have been made to minimise the study limitations as possible. Participants have been invited conveniently to participate in the online course using Facebook as a well-known social media platform. The principal investigator (RA) strived to improve the response rate, although the difficulties in controlling the online responses are common in online studies. However, only 248 participants were enrolled, and 87 of them completed all course requirements. The response rate can be improved by providing more training about using novel educational technologies, which will help participants complete online courses smoothly. Also, targeting more pharmacists and pharmacy students who are active on social media sites using specialised targeting tools will increase the response rate and the number of enrolled learners in online courses. Incentives also play an essential role in 
improving the response rate. Furthermore, political and war conflicts that erupted during the study period influenced the response rate negatively because of technical constraints.

Another limitation of this study was the one-group prepost design. This design has some limitations compared to the two-group experimental design of randomised controlled trials. Contamination affecting the measurement could have occurred, as the participants may have attended an educational event or course about generic medicines outside this cohort study. Test anxiety is another limitation of this design as taking the pre-test could affect participants' responses at the post-test measurement. Future studies should consider both passive and active control groups for more concrete results.

\section{Conclusions and recommendations}

Online learning has been successfully used in medical and pharmacy education globally. Using emerging online educational technologies and e-learning as novel educational tools in pharmacy education among ALSCs is still in its infancy. However, in this study, Arab pharmacists and pharmacy students expressed very positive views upon completing the online course through Schoology. They accessed online course materials efficiently, and their experience was flexible with life duties. The online modules on Schoology helped them improve their knowledge about generic medicines. Knowledge scores have increased significantly after the online educational intervention. Facebook and Schoology as web 2.0 tools have been implemented successfully, and the integration of these two tools showed promising results.

Researchers are encouraged to study the effectiveness of using Facebook alone as an educational platform or with other emerging web 2.0 tools. Also, two groups pre-test and post-test study design are recommended for future studies. Researchers are advised to use Facebook, Twitter, and other social media sites to reach subgroups of their target population and increase the response rate. Arab pharmacy education policymakers should consider these results to make pharmacy education more engaging and exciting for future millennial pharmacists. Furthermore, continuous professional development can also be done using emerging web 2.0 tools to stay updated with the pharmacy profession latest trends. This step is crucial in preparing future pharmacists to work smarter with artificial intelligence (AI) in the era of the fourth industrial revolution (4IR) and beyond.

\section{Conflicts of interest}

There were no conflicts of interest

\section{Acknowledgement}

Special thanks to Kotra Pharma and Prof. Dr Mohamed Azmi Hassali at the Universiti Sains Malaysia (USM) for the generous permission to digitalise the paper-based course about generic medicines.

\section{Funding}

The authors received no financial support for the research, authorship, and/or publication of this article.

\section{References}

Abdelhai, R., Yassin, S., Ahmad, M. F., \& Fors, U. G. (2012). An e-learning reproductive health module to support improved student learning and interaction: a prospective interventional study at a medical school in Egypt. BMC medical education, 12(1), 11. https://doi.org/10.1186/14726920-12-11

Abdulla, D. (2012). Attitudes of college students enrolled in 2 -year health care programs towards online learning. Computers \& Education, 59(4), 1215-1223.

https://doi.org/10.1016/j.compedu.2012.06.006

Alkoudmani, R. M., \& Elkalmi, R. M. (2015). Challenges to web-based learning in pharmacy education in Arabic language speaking countries. Archives of Pharmacy Practice, 6(3), 41. https://doi.org/10.4103/2045-080X.160989

Alkoudmani, R. M., Elkalmi, R. M., Apolinário-Hagen, J., Alkhoshaiban, A. S., \& Al-Essa, R. K. (2021). Pharmacists' Familiarity with E-learning in Transferring Pharmaceutical Knowledge in the Arab World. Archives of Pharmacy Practice, 1, 34. https://doi.org/10.51847/PgKZyJJYvF

Andrew, L., Ewens, B., Maslin-Prothero, S. (2015). Enhancing the online learning experience using virtual interactive classrooms. Australian Journal of Advanced Nursing, 32(4), 22-31.

Babiker, M. (2014). CHALLENGES AND FUTURE OF ELEARNING IN THE ARAB WORLD. INTED2014 Proceedings, 5156-5165.

Basak, S. K., Wotto, M., \& Bélanger, P. (2016). A framework on the critical success factors of e-learning implementation in higher education: A review of the literature. Int. J. Educ. Pedagog. Sci, 10(7), 2409-2414.

Bollmeier, S. G., Wenger, P. J., Forinash, A. B., \& Gleason, B. L. (2011). Impact of an online self-paced lecture to teach primary literature evaluation to second professional year students. Currents in Pharmacy Teaching and Learning, 3(2), 148-153. https://doi.org/10.1016/j.cptl.2011.01.001 
Bradshaw, M., \& Lowenstein, A. (2013). Innovative teaching strategies in nursing and related health professions: Jones \& Bartlett Publishers.

Cameron, A., \& Laing, R. (2010). Cost savings of switching private sector consumption from originator brand medicines to generic equivalents. World health report, 35, 210-215.

Conte, N. (2012). Pharmacists attitudes toward using the internet to satisfy their continuing education needs: An exploratory study. Currents in Pharmacy Teaching and Learning, 4(3), 180-187. https://doi.org/10.1016/j.cptl.2012.04.010

Crouch, M. A. (2009). An advanced cardiovascular pharmacotherapy course blending online and face-to-face instruction. American journal of pharmaceutical education, 73(3). https://doi.org/10.5688/aj730351

DiVall, M. V., Hayney, M. S., Marsh, W., Neville, M. W., O’Barr, S., Sheets, E. D., \& Calhoun, L. D. (2013). Perceptions of Pharmacy Students, Faculty Members, and Administrators on the Use of Technology in the Classroom. American journal of pharmaceutical education, 77(4). https://doi.org/10.5688/ajpe77475

Gadbury-Amyot, C. C., \& Brockman, W. G. (2011). Transition of a traditional pharmacology course for dental students to an online delivery format: a pilot project. Journal of dental education, 75(5), 633-645.

https://doi.org/10.5688/ajpe77475

Garcia, L. S., Amat, S. S., Garcia, N. M., \& Colomina, S. S. (2018). Schoology as an alternative to traditional teaching tools for university students. Paper presented at the 10th International Conference on Education and New Learning Technologies. https://doi.org/10.21125/edulearn.2018.1754

Gerdprasert, S., Pruksacheva, T., Panijpan, B., \& Ruenwongsa, P. (2010). Development of a web-based learning medium on mechanism of labour for nursing students. Nurse education today, 30(5), 464-469. https://doi.org/10.1016/j.nedt.2009.10.007

González-Gómez, F., Guardiola, J., Rodríguez, Ó. M., \& Alonso, M. Á. M. (2012). Gender differences in e-learning satisfaction. Computers \& Education, 58(1), 283-290. https://doi.org/10.1016/j.compedu.2011.08.017

Hall, D. L., Corman, S. L., Drab, S. R., Smith, R. B., \& Meyer, S. M. (2010). Application of a technology-based instructional resource in diabetes education at multiple schools of pharmacy: evaluation of student learning and satisfaction. Currents in Pharmacy Teaching and Learning, 2(2), 108-113. https://doi.org/10.1016/j.cptl.2010.01.007

Hassali MA, e. a. (2012). Understanding Generic Medicines: What Health Care Professionals Should Know. Malaysia: Kotra Pharma.

Huynh, R. (2017). The role of E-learning in medical education. Academic Medicine, 92(4), 430-430. https://doi.org/10.1097/ACM.0000000000001596

Joshua, J. N., Swastika, I. P. A., \& Estiyanti, N. M. (2016). The effectiveness of e-learning implementation using social learning network schoology on motivation \& learning achievement. Jurnal Nasional Pendidikan Teknik
Informatika: JANAPATI, 5(1), 28-33.

https://doi.org/10.23887/janapati.v5i1.9914

Karaksha, A., Grant, G., Anoopkumar-Dukie, S., Nirthanan, S. N., \& Davey, A. K. (2013). Student engagement in pharmacology courses using online learning tools. American journal of pharmaceutical education, 77(6). https://doi.org/10.5688/ajpe776125

Kheir, N., Zaidan, M., Younes, H., El Hajj, M., Wilbur, K., \& Jewesson, P. J. (2008). Pharmacy education and practice in 13 Middle Eastern countries. American journal of pharmaceutical education, 72(6). https://doi.org/10.5688/aj7206133

Koch, J., Andrew, S., Salamonson, Y., Everett, B., \& Davidson, P. M. (2010). Nursing students' perception of a web-based intervention to support learning. Nurse education today, 30(6), 584-590. https://doi.org/10.1016/j.nedt.2009.12.005

Lee, L. A., Wang, S. L., Chao, Y. P., Tsai, M. S., Hsin, L. J., Kang, C. J., Fu, C. H., Chao, W. C., Huang, C. G., Li, H. Y., \& Chuang, C. K. (2018). Mobile Technology in E-Learning for Undergraduate Medical Education on Emergent Otorhinolaryngology-Head and Neck Surgery Disorders: Pilot Randomized Controlled Trial. JMIR medical education, 4(1), e8. https://doi.org/10.2196/mededu.9237

Lewis, K. O., Cidon, M. J., Seto, T. L., Chen, H., \& Mahan, J. D. (2014). Leveraging e-learning in medical education. Current problems in pediatric and adolescent health care, 44(6), 150163. https://doi.org/10.1016/j.cppeds.2014.01.004

Meckfessel, S., Stühmer, C., Bormann, K. H., Kupka, T., Behrends, M., Matthies, H., Vaske, B., Stiesch, M., Gellrich, N. C., \& Rücker, M. (2011). Introduction of e-learning in dental radiology reveals significantly improved results in final examination. Journal of cranio-maxillo-facial surgery, 39(1), 40-48. https://doi.org/10.1016/j.jcms.2010.03.008

Mohamed Azmi H, Z. S., Fahad S, Maryam F, Hisham A. (2012). Assessment of Student's Perceptions Towards Elearning Management System (ELMS) In A Malaysia Pharmacy School: A Descriptive Study. Malaysian Journal of Public Health Medicine, 12(1), 14-20.

Öztürk, D., \& Dinç, L. (2014). Effect of web-based education on nursing students' urinary catheterization knowledge and skills. Nurse education today, 34(5), 802-808. https://doi.org/10.1016/j.nedt.2013.08.007

Pallant, J. (2020). SPSS survival manual: A step by step guide to data analysis using IBM SPSS: Routledge. https://doi.org/10.4324/9781003117445

Peska, D. N., \& Lewis, K. O. (2010). Uniform instruction using web-based, asynchronous technology in a geographically distributed clinical clerkship: analysis of osteopathic medical student participation and satisfaction. The Journal of the American Osteopathic Association, 110(3), 135-142.

Ried, L. D. (2010). A distance education course in statistics. American journal of pharmaceutical education, 74(9). https://doi.org/10.5688/aj7409172

Schlager, D. (2016). Schoology: The adoption of a learning management system. 
Sicat, A. S., \& Ed, M. (2015). Enhancing college students' proficiency in business writing via Schoology. International Journal of Education and Research, 3(1), 159-178.

Suana, W., Maharta, N., Nyeneng, I. D., \& Wahyuni, S. (2017). Design and implementation of schoology-based blended learning media for basic physics I course. Jurnal Pendidikan IPA Indonesia, 6(1).

https://doi.org/10.15294/jpii.v6i1.8648

Sudarwati, N. (2018). Evaluating E-Learning as a Learning Media: A Case of Entrepreneurship E-Learning using Schoology as Media. International Journal of Emerging Technologies in Learning, 13(9).

https://doi.org/10.3991/ijet.v13i09.7783

Tezci, E., Karaca, D., \& Sezginsoy, B. (2008). The Study of Reliability and Validity of Creative Materials. Turkish Online Journal of Educational Technology, 7(1):46-57

Woerkom, M. v., Piepenbrink, H., Godman, B., Metz, J. d., Campbell, S., Bennie, M., Eimers, M., \& Gustafsson, L. L. (2012). Ongoing measures to enhance the efficiency of prescribing of proton pump inhibitors and statins in The Netherlands: influence and future implications. Journal of comparative effectiveness research, 1(6), 527-538.

https://doi.org/10.2217/cer.12.52

Yusoff, M. S. B. (2019). ABC of content validation and content validity index calculation. Resource, 11(2), 49-54. https://doi.org/10.21315/eimj2019.11.2.6 